\section{Controlled Cathode Sputtering}

THE object of these experiments is to obtain accurate measurements relating to the phenomenon of cathode disintegration in gaseous discharges.

The apparatus consists essentially of a strong ionsource of the Lamar-Samson-Compton type ${ }^{1}$, capable of delivering 2 milliamperes of singly-charged argon ions, and of an adjacent 'sputtering chamber' main. tained at about $2 \times 10^{-4} \mathrm{~mm}$. mercury pressure, where the material to be tested is sputtered and measurements relating to that process are made.

The first objective is to obtain measurements of the amount of material sputtered per unit time as a function of the ion-current density and ion-energy. As shown in the diagram (Fig. 1), the ions emerging

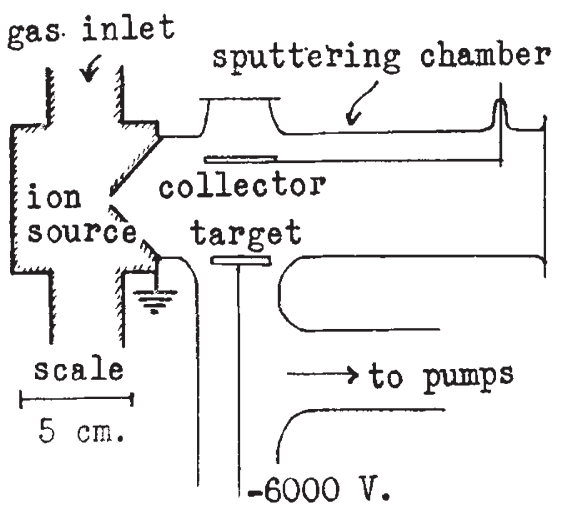

Fig. 1.

from the source (which is earthed) are allowed to impinge on and sputter a target maintained at a negative potential. Some of the material sputtered is deposited on a mica collector placed in front of the target, and supported by a horizontal fine quartz fibre. The weight of the deposit collected a few milligrams) can readily be determined by observing the deflection of the fibre by means of a microscope. This allows measurement of the relative rates of sputtering. The total amount of material sputtered can be computed in cases where the law of angular distribution of sputtered deposit over a sphere is known ${ }^{2}$.

The rate of sputtering of gold by argon ions of 6,000 volt energy has been determined. The sputtering rate is sufficient to deposit measurable amounts in $3 \frac{1}{2}$ hours. With decreasing ion energy the rate of deposition decreases, and for ions of 2,000 volt energy, about 10 hours would be required to deposit a measurable amount. This is the maximum period over which the apparatus has been operated steadily. Because of the complicated nature of the apparatus, it seems impracticable to extend the time of the test. Therefore to obtain the rates of sputtering at lower voltages a construction of the sputtering chamber has been achieved, which still allows weight determinations, and in addition permits light transmissivity measurements of sputtered deposits.

The determination of the rate of sputtering of a given substance is complicated in some instances by a copious secondary electron emission from the bombarded target. Thus the apparatus is used at present in a somewhat modified arrangement. for stindy of this secondary electron emission from solid metals bombarded by argon ions.

Gregory Timoshenko.

Department of Electrical Engineering,

Massachusetts Institute of Technology. April 20.

${ }^{1}$ Phys. Rev., 48, 886 (1935).

2 Seeliger and Sommermeyer, Z. Phys., 93, 692 (1935).

\section{X-Ray Intensifying Screens adapted to Structure Analysis}

ThE intensifying screens in use for medical radiography cannot be employed to reduce times of exposure when working on tissue fibres, as they are not sensitive to the radiation used in structure analysis. However, Messrs. Ilford, Ltd., London, have now produced a screen, the Ilford Fluorazure intensifying screen (Levy-West), which proves to be very suitable for this purpose ; this screen was put at our disposal by Mr. Chr. J. Bruno Wittgrefe, of the X-Ray Section, Ilford Co., to whom our best thanks are due for this kindness.

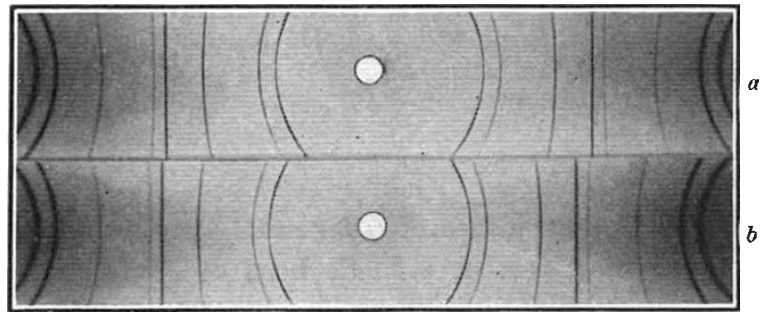

Fig. 1.

X-RAY PHOTOGRAPH OF A COPPER WIRE, TAKEN AT $40 \mathrm{KV}$. (a) ILFORD FILM WITHOUT SCREEN; EXPOSURE 45 MIN. (b) ILFORD FILM WITH A FLUORAzURE SCREEN AT THE BACK; EXPOSURE 15 MIN

While we expected that increase of line width would counteract the advantages from eventual intensifying to such an extent that the photographs obtained would only be suitable for approximate work and not for exact measurements, we were quite astonished to find not only actual intensifying (3 times at $40 \mathrm{kV}$.) but moreover practically no increase of width, which seems a very important feature in the new screen. As appears from the photographs reproduced herewith (Fig. 1), it has proved possible to obtain films suitable for exact measurements. The photographs were taken with a Philips Metalix tube with copper-anticathode and a nickel filter of $0.01 \mathrm{~mm}$. The Debye-Scherrer camera had a radius of $2.77 \mathrm{~cm}$., while the diaphragm consisted of two pinholes $0.5 \mathrm{~mm}$. diameter, separated by $6 \mathrm{~cm}$. A copper wire of $0.6 \mathrm{~mm}$. diameter was taken as a sample. Unless otherwise stated, the photographs were taken at $40 \mathrm{kV}$. and $15.5 \mathrm{~m}$.amp.

First a photograph was taken on an Agfa-Lane film, the usual material for structure analysis. Proper blackening was obtained after 75 min. exposure. Then the experiment was repeated using an Ilford film. To get the same blackening as in the former case, an exposure of $45 \mathrm{~min}$. proved to be necessary. The grain of the Ilford film is slightly coarser, but still within admissible limits (see Fig. 1, a). Thirdly, 